\title{
The Survey of Corpus-assisted English Writing of Chinese Non-English Majors
}

\author{
Hai-ying Liu \\ Foreign Languages Department,Chongqing University of Arts and Sciences,Chongqing, China
}

731417532@qq.com

Keywords: survey, English writing, corpus, non-English majors

Abstract. This study aims at the application of corpora in English writing among non-English majors at Chongqing University of Arts and Sciences. The result presents that Chinese non-English majors have positive attitudes by applying corpora in English writing. It also suggests that corpora can strengthen learners' confidence, writing skills, phrase-usage, and other aspects in English writing. The results of the study have the practical significance in teaching and learning English writing.

\section{Introduction}

In recent years, many foreign scholars have begun to research on how to apply corpora to the teaching of English writing. The results show that the use of corpora can promote the learning of English writing. It is helpful to solve the problems of vocabulary, grammar in foreign language writing, which can promote the learners' foreign language writing ability. Therefore, they support the use of corpora in foreign language writing [1, 2, 3, 4].

\section{The application of corpora in foreign language writing}

The application of corpora in teaching of English writing has been focused in recent year in foreign countries. However, the existing researches on the corpus-aided foreign language writing are based on the second language learners in foreign countries [1, 2, 3, 4]. Only a few existing studies took English majors at universities in China as the objects [5]. Do corpora improve the learning of English writing among non-English majors at Chinese universities?

The study aimed to answer the following three questions:

(1) What aspects of the corpus do Chinese non-English majors think are helpful in the study of foreign language writing? (2) What are the difficulties of Chinese non-English majors in the application of corpora in foreign language writing? (3) What are the attitudes of Chinese non-English majors in the application of corpora in foreign language writing?

\section{Research Methodology. Objects.}

The objects are all non-English majors of Grade 2013 at Chongqing University of Arts and Sciences. They learnd English as a compulsory course lasting for 4 semesters, with 64 periods every semester. The students, who were in the same class, were in the fourth semester of learning. 
The course provided the students with the corpus of contemporary American English (COCA) as the corpus for training. Each student can use a computer after class. The guidance of the teacher can be delivered to the QQ group of the class. At the end of the term, the questionnaire-survey was carried out to study their views on students' application of the corpus in English writing. A total of 56 students participated in it, who were college students majoring in telecommunication.

Research tools. The questionnaire includes 27 questions in the following three tables.

\section{Results. In what ways do corpora improve the foreign language writing?}

Table 1. The views of the learners on the corpus-assisted foreign language writing

\begin{tabular}{|l|l|l|}
\hline Item & Mean & Standard Deviation \\
\hline Word-usage & 4.51 & 1.31 \\
\hline Phrase-usage & 4.63 & 1.34 \\
\hline Meaning of words & 4.33 & 1.65 \\
\hline Writing skills & 5.15 & 1.67 \\
\hline Strengthening learners' confidence & 5.63 & 1.46 \\
\hline Grammar & 3.76 & 1.58 \\
\hline Foreign language test & 3.66 & 1.43 \\
\hline Reading skills & 3.64 & 1.72 \\
\hline
\end{tabular}

Note: 1: unhelpful completely; 2: unhelpful; 3: unhelpful to some degree; 4: helpful to some degree 5: helpful; 6: very helpful.

Generally speaking, most students think that the corpus is helpful in the 8 items in Table 1 , with all the means over 3. The learners believe that the corpus is helpful in the following 3 aspects, strengthening learners' confidence, writing skills, phrase-usage with the three highest scores. The use of the corpus may increase the language input, then inspire the learners' confidence and promote the ability of language output in the process of writing. The significant advantage of the corpus is phrases derived from the corpus and automatic data analysis, which is helpful to learners' understanding of the usage of phrases.

The following 3 items got the lowest scores: grammar, foreign language test, reading skills, with the means 3.76, 3.66, 3.64 respectively. Maybe because the improvement of reading skills and the ability of foreign language testing contain more skills, and the language information required is more, so the short-term use of corpora in these two items got the lowest scores. Grammar also possesses a lot of information, since the corpus can not offer the systematic grammar knowledge, which may be the reason that it gets the third lowest score.

What are the difficulties in using corpora in foreign language writing? 
Table 2. Results of students' difficulties in the application of the corpus in writing

\begin{tabular}{|l|l|l|}
\hline Item & Mean & Standard Deviation \\
\hline Too much time needed for data analysis & 3.27 & 1.52 \\
\hline Limited retrieval output of sentences & 1.23 & 1.43 \\
\hline Retrieval output is not complete & 2.45 & 1.59 \\
\hline Analysis of output data of collocation & 3.67 & 1.76 \\
\hline Search new words in the collocation & 2.55 & 1.34 \\
\hline Speed & 2.61 & 1.54 \\
\hline The real text is too difficult & 3.54 & 1.35 \\
\hline Data analysis of the retrieval output & 3.89 & 1.78 \\
\hline Retrieval technology & 3.35 & 1.65 \\
\hline Retrieval output of too many sentences & 3.80 & 1.22 \\
\hline The use of computers or network is not convenient & 1.37 & 1.24 \\
\hline
\end{tabular}

Note: 1 very simple; 2 simple; 3 simple to some degree; 4 difficult to some degree; 5 difficult; 6 very difficult

In all, the average scores are all bellow 4.00, which indicates most learners think that the use of the corpus in Table 2 is not too difficult, because they were trained in this course and the corpus was not difficult to operate. The most difficult in corpus-aided writing is data analysis and too much sentence-output. This indicates that the amount of the retrieval output is too much which may be one of the main reasons for the difficulty of data analysis. The item, the real text is too difficult, got the third highest score, which may mean the native language is difficult for the learners, since they are non-English majors who still need offer more efforts in English.

The item, limited retrieval output of sentences, got the lowest score since the retrieval output of sentences is large on the opposite. The item, the use of computer or network is not convenient, got the second lowest score, because computers were popular among college students, and the network was of high-quality. The item, retrieval output is not complete, got the third lowest score, which may result from the fact: even the retrial output is not complete as passages, but it still contains several complete sentences, so it is acceptable and available for the students.

\section{What are the learners' attitudes after they apply the corpus in foreign language writing?}

Table 3. Result of the learners' use of the corpus in writing

\begin{tabular}{|l|l|l|}
\hline Item & Mean & Standard Deviation \\
\hline Retrieval technique is simple and easy to learn & 4.78 & 1.65 \\
\hline $\begin{array}{l}\text { Exercises are helpful in learning retrieval } \\
\text { technology }\end{array}$ & 5.59 & 1.43 \\
\hline Information retrieval is easy & 5.28 & 1.66 \\
\hline Confidence for information retrieval for & 5.67 & 1.67 \\
\hline $\begin{array}{l}\text { Using index or collocation to search } \\
\text { information is helpful in writing }\end{array}$ & 4.56 & 1.86 \\
\hline Always getting the information from the corpus. & 3.12 & 1.45 \\
\hline Choosing corpora independently & 4.93 & 1.51 \\
\hline The more you learn, the more you like corpora. &
\end{tabular}

Note: 1strong opposition; 2opposition; 3 opposition to some extent; 4 agreement to some extent; 5 agreement; 6 strong agreement 
Generally speaking, the average scores of main items mainly range between 3 and 5, which indicate that most learners have positive attitudes towards the use of the corpus in writing. The most significant of the 8 items listed in Table 3 is the following. The item, using index or collocation to search for information is helpful in language learning, got the highest score, which means the learners believe the corpus is really useful in the help of their language writing.

The item, choosing corpora independently, got the lowest score, which may stem from the fact that they are non-English majors, who don't need corpora as much as the English majors, and may think choosing corpora is not so necessary.

\section{Summary}

The research results show that Chinese non-English majors have a positive attitude to the use of corpora in foreign language writing. Corpora have a certain feasibility and development in the process of foreign language writing.

This study has some limitations: the number of objects is small, and the corpus used is just one. Only 56 students participated in the surveys, who major in telecommunication. Future research can be expanded to other professions and other grades.

\section{References}

[1] A.C. Fuentes, P. Rokowski, Use of Corpus in the Business English Classroom: From Lesser to More Specific, Database: ERIC Report ( 2002) 15 pp.

[2] S. Çelik, M. Elkatmiş, The Effect of Corpus Assisted Language Teaching on the Learners' Proper Use of Punctuation Marks, Educational Sciences: Theory \& Practice Vol. 13 Issue 2 ( 2013 ) 1090-1094.

[3] C.Kennedy and T. Miceli, Corpus-Assisted Creative Writing: Introducing Intermediate Italian Learners to a Corpus as a Reference Resource, Language Learning and Technology (2010).

[4] H. Yoon, More than a Linguistic Reference: the Influence of CorpusTechnology on L2 Academic Writing, Language Learning and Technology (2008) .

[5] Y. Zhang and L. Lei, Survey on ChineseCollege Students' Attitudes on Corpus-assisted Foreign Language Writing, Contemporary Foreign Language Research Issue 4 ( 2015) 549-556.

This paper is the research result of the key project of " the Twelfth Five-Year Plan" in

National Educational Science (GPA115070 Research on the Application of Corpora in the Compilation of College Textbooks and the Teaching in Foreign Languages) . 